Revista Monografias Ambientais

Santa Maria, v. 14, n. 3, set-dez. 2015, p. 10-17

Revista do Centro de Ciências Naturais e Exatas - UFSM

ISSN : 22361308

\title{
Avaliação de Impactos Ambientais: Estudo de caso no Cemitério Público do município de Queimadas - PB
}

\author{
Environmental Impact Assessment: Case Study in Public Cemetery in the city of Queimadas - PB \\ Pedro José Aleixo dos Santos, Claudeam Martins da Gama, Lívia Poliana Santana Cavalcante, Vera \\ Lúcia Antunes de Lima
}

Universidade Federal de Campina Grande, UFCG.

\begin{abstract}
Resumo
É inegável a importância do cemitério para a sociedade, seja do ponto de vista cultural, espiritual, sanitário, entretanto, por se tratar de um empreendimento que oferece alto risco de poluição ao meio ambiente e impacto psicológico à população é motivo de polêmica e preocupação por parte de vários setores da sociedade. Diante deste contexto, este estudo tem como objetivo descrever e avaliar os impactos ambientais provenientes das atividades sepultamento realizados no cemitério público no município de Queimadas - PB. Adotou-se como instrumentos de pesquisa: visitas in loco, através da qual foi realizada a observação direta e registro fotográfico do cemitério em estudo, bem como conversas informais com moradores residentes próximos ao empreendimento. Os resultados foram quantificados através de uma Matriz de Leopold adaptada, na qual foram consideradas as dimensões físicas, químicas, biológicas e antropológicas da localidade estudada. Considerando as atividades sepulcrais no cemitério público municipal da cidade de Queimadas, é possível apontar que, mesmo em condições adversas no âmbito físico, como por exemplo, quando se trata do relevo do terreno, a implementação de suas atividades é considerada viável, visto que no contexto histórico da urbanização da cidade em que está localizado, suas atividades precederam a construção de residências e pavimentação de seu entorno, no entanto, neste quesito, considera-se como relevante a adoção de estratégias para a drenagem e pré-tratamento do necrochorume gerado a partir da decomposição dos finados sepultados.
\end{abstract}

Palavras-chave: Avaliação de Impacto Ambiental. Cemitério. Necrochorume.

\begin{abstract}
There is no denying the importance of the cemetery to society, whether cultural, spiritual, health point of view, however, because it is an enterprise that offers high risk of pollution to the environment and psychological impact on the population is a source of controversy and concern part of various sectors of society. Given this context, this study aims to describe and evaluate the environmental impacts from the burial activities carried out in the public cemetery in the municipality of Queimadas - PB. It was adopted as research tools: on-site visits, through which was conducted direct observation and photographic record of the cemetery under study as well as informal conversations with residents living near the project. The results were quantified through a Leopold Matrix adapted, which considered the physical, chemical, biological and anthropological study of the locality. Considering the burial activities in the municipal cemetery of the town of Queimadas, you can point out that even in adverse conditions in the physical realm, for example, when it comes to the form of the land, the implementation of its activities is considered viable, whereas in historical context of urbanization of the city in which it is located, its activities preceded the construction of apartment blocks and paving their surroundings, however, in this regard, it is considered as relevant the adoption of strategies for drainage and pretreatment necrochorume generated from the decomposition of buried deceased.
\end{abstract}


Santos et al:: Avaliação de Impactos Ambientais: Estudo de caso no Cemitério

\section{Introdução}

Segundo Leli et al. (2012) "Koumeterian", ou cemitério, é uma palavra de origem grega que significa "onde eu durmo". Com o surgimento do Cristianismo esse termo assumiu o sentido de local destinado ao repouso final pós-morte, atribuindo significado apenas para lugares onde acontece o enterro dos cadáveres por inundação, ou seja, no solo, sendo também conhecido como: necrópole, campo santo, sepulcrário entre outros.

Na Idade Média europeia, os mortos eram enterrados nas igrejas e imediações, com o intuito de promover uma relação de aproximação entre vivos e mortos, no entanto, sua realização desencadeou o surgimento de diversas epidemias, à exemplo o tifo e a peste negra. No século XVIII foram tomadas medidas sanitárias na Europa que até hoje são adotadas da realização de sepultamentos em áreas abertas, conhecidas como cemitérios campais ou campos-santos, localizadas distante do perímetro urbano, (LELI, et al.,2012).

A expansão urbana das cidades e o seu transbordamento aliado ao crescimento populacional foram fatores preponderantes para que os cemitérios coletivos a céu aberto passassem a ser criados devido o aumento da demanda e falta de espaço para sepultamentos nas igrejas e capelas. É inegável a importância do cemitério para a sociedade, seja do ponto de vista cultural, espiritual, sanitário, entretanto, por se tratar de um empreendimento que oferece alto risco de poluição ao meio ambiente e impacto psicológico à população é motivo de polêmica e preocupação por parte de vários setores da sociedade.

Com base nos parâmetros legais e normativos que dispõe do trato de atividades impactantes, o sepultamento de cadáveres corresponde a uma fonte poluidora do meio físico podendo ser caracterizado como aspecto ambiental significativo. Vale a ressalva de que conforme a ISO 14.001: 2004 elementos das atividades, produtos ou serviços de uma organização que pode interagir com o meio ambiente, ou seja, as atividades, produtos ou serviços sobre o meio ambiente que causam um impacto ambiental significativo (BRASIL, 2004).

Atentamos para o fato de que os cemitérios nunca foram incluídos nas listas de fontes tradicionais de contaminação ambiental, no entanto, mesmo não sendo classificada como atividade comercial ou industrial, Silva e Filho (2008) defendem que sua realização pode provocar o vazamento de substâncias provenientes de resíduos biológicos com potencial poluídos ao solo e águas subterrâneas.

Nesse sentido, Sánchez (2008) defende que a implementação de um empreendimento deve ser precedida da Avaliação de Impactos Ambientais- AIA, através do qual é possível identificar, interpretar e comunicar consequências sobre a saúde e bem-estar humano, configurando-o como um instrumento para a gestão ambiental.

A AIA é uma atividade com o objetivo de identificar e predizer o impacto no ambiente e na saúde pública, contribuindo para a formulação de propostas legislativas, programas de desenvolvimento, bem como de interpretar e comunicar informações à população sobre seus impactos (SÀNCHEZ, 2008), sendo relevante por contribuir para a informação sobre um determinado projeto, permitindo a orientação e tomada de decisão da população em relação ao mesmo, com menos emotividade, eliminando a influência tanto de grupos políticos como de grupos econômicos.

Diante deste contexto, este estudo tem como objetivo descrever e avaliar os impactos ambientais provenientes das atividades sepultamento realizados no cemitério público no município de Queimadas - PB. 


\section{Fundamentação Teórica}

\subsection{Critérios para a implementação de cemitérios conforme o CONAMA}

Cemitérios podem provocar relevantes impactos ambientais na região em que estão instalados. As Resoluções CONAMA (Conselho Nacional do Meio Ambiente) 335/2003 e a 402/2008, regulamentam e estabelecem critérios mínimos que devem ser integralmente cumpridos na confecção dos projetos de implantação de cemitérios como forma de garantir a decomposição normal do corpo e proteger as águas subterrâneas da infiltração do necrochorume e contaminação do solo (ALBOQUERQUE; CERQUEIRA; BARBOSA, 2012).

De acordo com o Art. $1^{\circ}$ Resolução 335/2003 do CONAMA:

Os cemitérios horizontais e os cemitérios verticais, doravante denominados cemitérios, deverão ser submetidos ao processo de licenciamento ambiental, nos termos desta Resolução, sem prejuízo de outras normas aplicáveis à espécie.

Em seu artigo 5º, a mesma Resolução estabelece que:

O perímetro e o interior do cemitério deverão ser providos de um sistema de drenagem adequado e eficiente, destinado a captar, encaminhar e dispor de maneira segura o escoamento das águas pluviais e evitar erosões, alagamentos e movimentos de terra; (inciso acrescentado pela Resolução n³68/06).

\subsection{O Necrochorume}

Segundo Silva \& Filho (2008) a principal causa da poluição ambiental pelos cemitérios é o necrochorume, líquido liberado intermitentemente pelos cadáveres em processo de decomposição, no entanto ao longo do processo de putrefação são liberados também os gases funerários, principalmente o gás sulfídrico (H2S), o dióxido de carbono $\left(\mathrm{CO}_{2}\right)$, as mercaptanas, o gás metano $\left(\mathrm{CH}_{4}\right)$, a amônia $\left(\mathrm{NH}_{3}\right)$ e o fosfina $\left(\mathrm{PH}_{3}\right)$ - hidratode fósforo, incolor e inflamável.

Esse líquido viscoso é mais denso que a água $\left(1,23 \mathrm{~g} / \mathrm{cm}^{3}\right)$, rico em sais minerais e substâncias orgânicas degradáveis, elevada DBO, de coloração castanho-acinzentado, polimerizável, e grau variado de patogenicidade O necrochorume é constituído por $60 \%$ de água, $30 \%$ de sais e $10 \%$ de substâncias orgânicas variadas (SILVA,1998; MATOS, 2001).

Encontra-se no necrochorume números elevados de microrganismos, com ênfase a bactérias heterotróficas, proteolíticas e lipolíticas. São exemplos de microrganismos presentes na decomposição de organismos animais:

Escherichia coli, Enterobacter, Klebsiella Citrobacter e a Streptococcus faecalis, e microrganismos patogênicos como Clostridium perfringes, Clostridium welchii - estes causam tétano, gangrena gasosa e toxi-infecção alimentar; Salmonella typhi que causa a febre tifóide e S. paratyphi a febre paratifóide, Shigella causadora da desinteira bacilar e o vírus da hepatite A (SILVA; FILHO, 2008, p. 30).

A penetração do necrochorume no subsolo poder culminar na contaminação das águas subterrâneas e superficiais, quando estas entram em contato com o processo de decomposição dos cadáveres que acabam liberando os microrganismos supracitados.

\section{Metodologia}

O estudo foi realizado no período de 14 de novembro a 25 de dezembro de 2014, no município de Queimadas, região Metropolitana de Campina Grande, agreste paraibano. Está situado entre a latitude $7^{\circ} 21^{\prime} 28^{\prime \prime}$ S, e longitude $35^{\circ} 53^{\prime} 52^{\prime \prime}$ W (Figuras 1 e 2), possui uma área de $401,776 \mathrm{~km} 2$ e uma população de 42,516 habitantes (IBGE, 2013). O local escolhido para estudo foi o Cemitério 


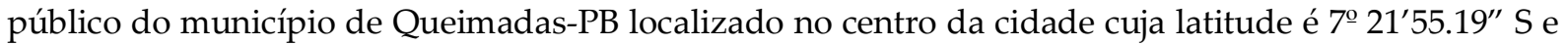
longitude 35은 $54^{\prime} 24.46^{\prime \prime}$ W (Figura 3).
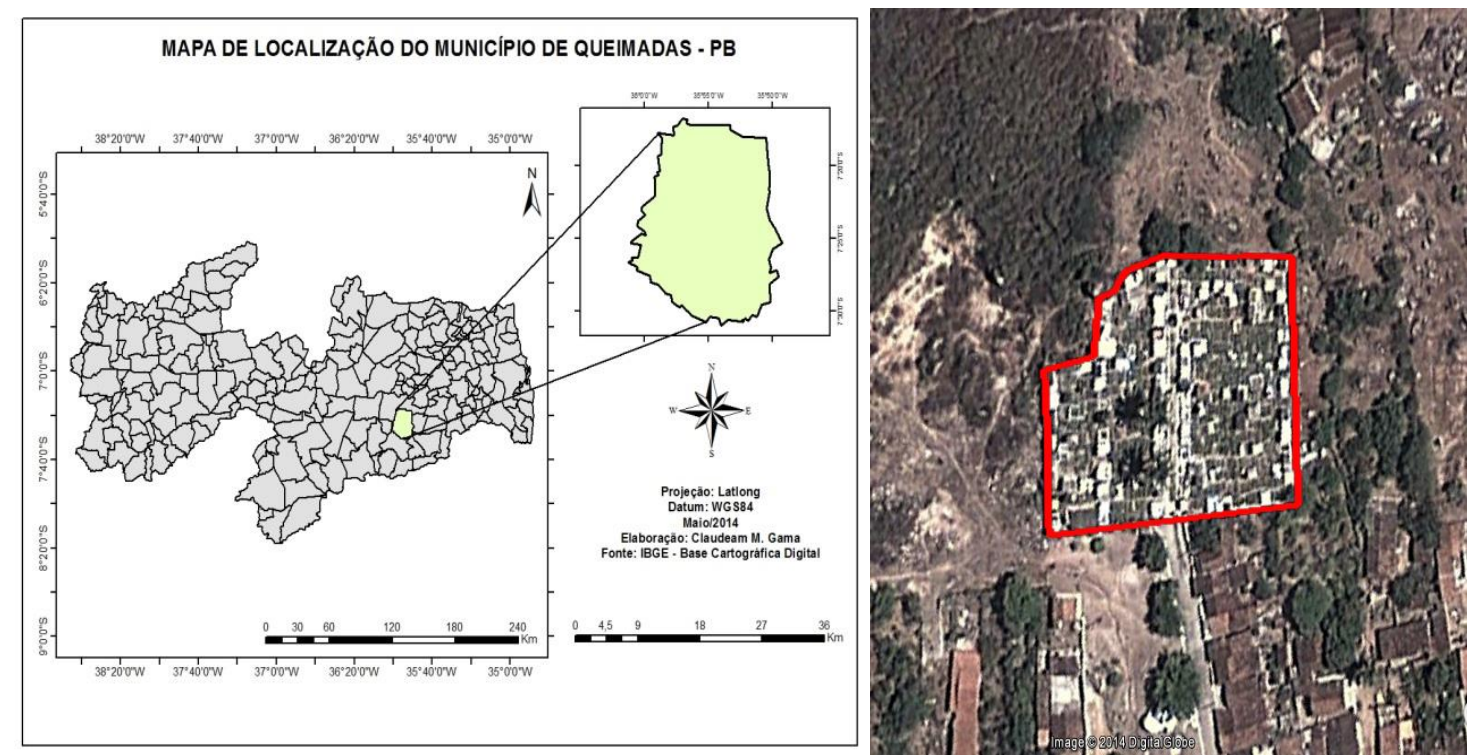

Figuras 1 e 2: Mapa de localização do município de Queimadas-PB e vista aérea do cemitério de Queimadas-PB. Queimadas - PB, 2014. Fonte: Autores.

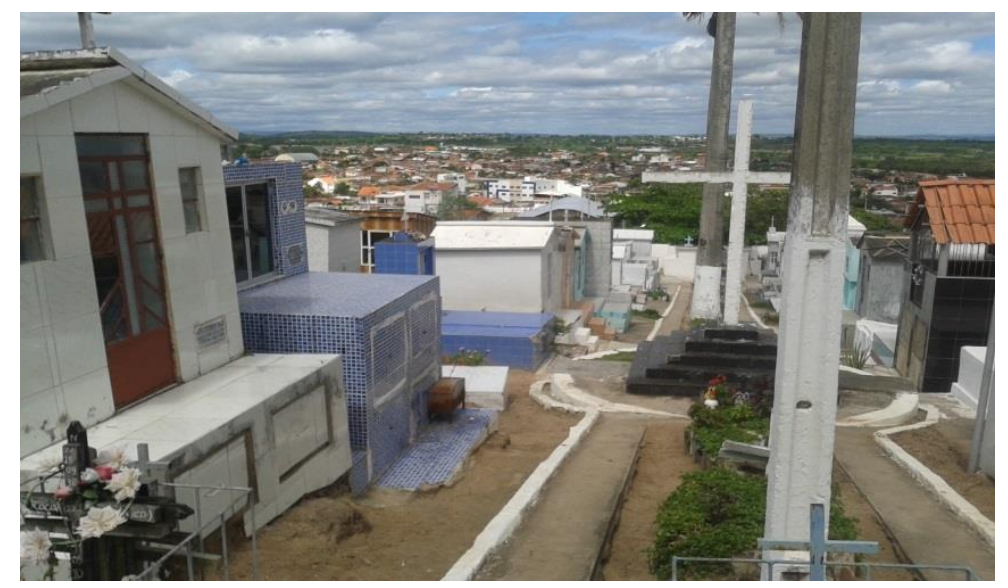

Figura 3. Cemitério público do município de Queimadas. Queimadas - PB, 2014. Fonte: Autores

Adotou-se como instrumentos de pesquisa: visitas in loco, através da qual foi realizada a observação direta e registro fotográfico do cemitério em estudo, bem como conversas informais com moradores residentes próximos ao empreendimento. Os resultados foram quantificados através de uma Matriz de Leopold adaptada (Quadro 1), na qual foram consideradas as dimensões físicas, químicas, biológicas e antropológicas da localidade estudada, bem como as magnitudes "Pouco importante","Médio importante" e "Muito importante" como forma de qualificar os impactos observados. Posteriormente os dados da matriz foram interpretados e discutidos com o auxílio da literatura científica pertinente à temática.

\section{Resultados e Discussão}

Os resultados foram quantificados através de uma Matriz de Leopold adaptada de Albuquerque et al., 2012 (Quadro 1), na qual foram consideradas as dimensões físicas, químicas, biológicas e antropológicas da localidade estudada, bem como as magnitudes "Pouco importante", "Médio importante" e "Muito importante" como forma de qualificar os impactos observados. 
Quadro 1. Matriz de Leopold usada para o diagnóstico dos impactos ambientais do cemitério de Queimadas-PB. 2014. Adaptada de Albuquerque et al., (2012).

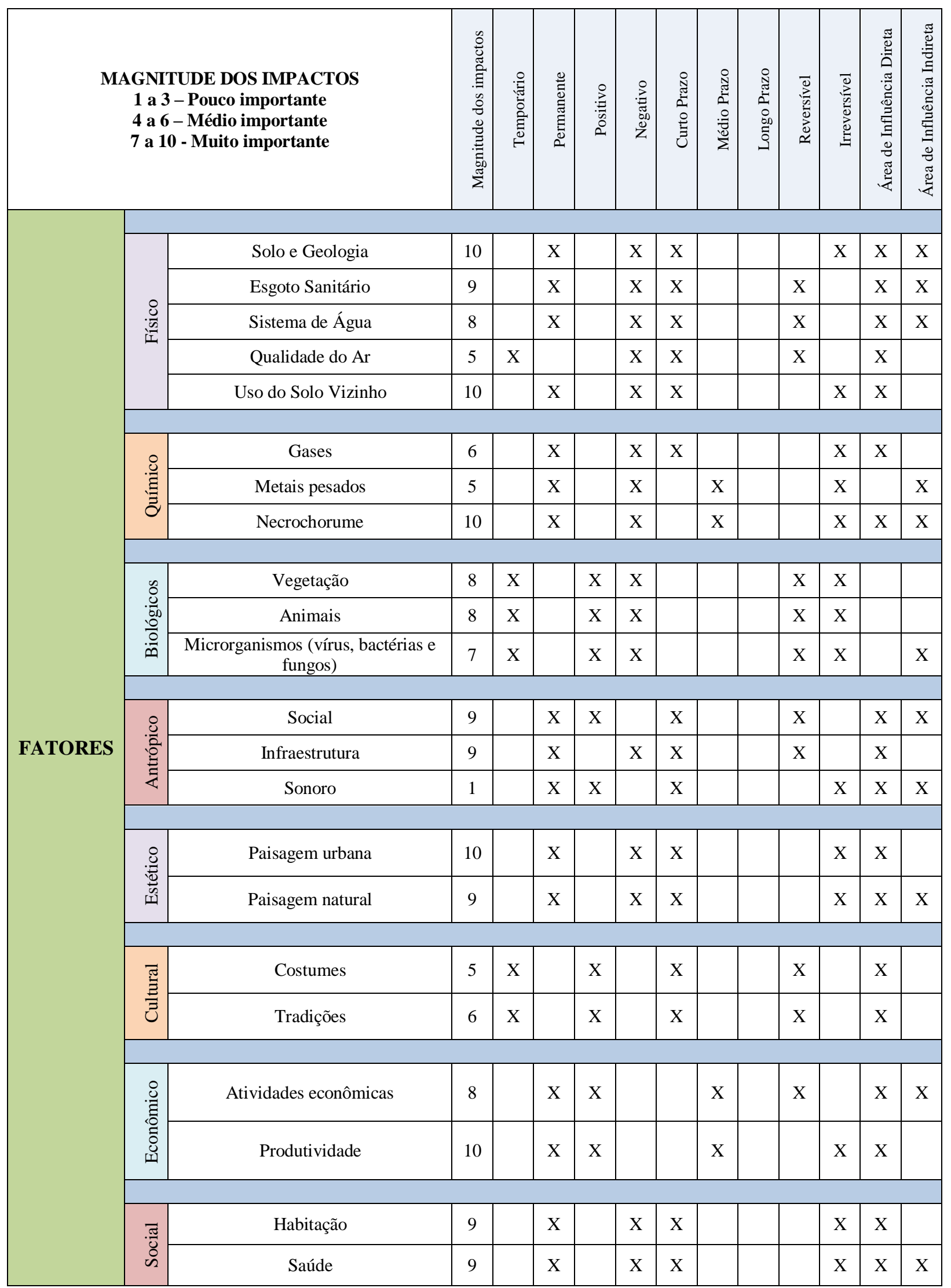




\subsection{Impactos físicos}

Foram consideras com magnitude muito importante: solo e geologia, esgoto sanitário, sistema de água e uso do solo vizinho (permanente), nesses itens ocorre à descaracterização topográfica para construir edificações vias de acesso, problemas ocasionados pela erosão da água das chuvas assim como o assoreamento de mananciais superficiais devido a implantação do empreendimento, a contaminação do subsolo e das águas superficiais do entorno pelo necrochorume que dependerá muito da vulnerabilidade física do local e do sistema de drenagem.

Como médio importante, a qualidade do ar (temporário), neste item pensou-se na possiblidade de impactos no local no momento da escavação, terraplanagem do terreno, na abertura de vias de acesso e na construção de edificações, o que pode ter aumentado à concentração de $\mathrm{CO}_{2} \mathrm{e}$ outros materiais particulados fugitivos devido a presença de veículos, maquinas e equipamentos. Em relação à natureza todos foram negativos e a temporalidade classificou-se como curto prazo, para todos os itens.

Os itens solo e geologia e uso do solo vizinho forma considerados irreversíveis. Reversível apresentaram-se esgoto sanitário e sistema de água foram considerados como influência direta, os demais campos ficaram como influência direta.

\subsection{Impactos químicos}

No ambiente químico foram compreendidas de relevância moderada as variáveis: metais pesados e gases, cujo impacto é permanente, negativo e irreversível. Os gases foram considerados como impactos de curto prazo e área de influência direta, enquanto que os metais pesados médio prazo e área de influência indireta. Foi considerado de alta relevância (magnitude 10) o impacto provocado pelo necrochorume.

O processo de putrefação ocorre devido a ação microbiológica, cuja velocidade se dá por razões intrínsecas (idade, causa mortal ou constituição do corpo) e extrínsecas (umidade, aeração, condições mineralógicas do solo, temperatura, entre outros), tendo como pro um de seus principais produtos resultantes o necrochorume.

No ambiente natural, o necrochorume é convertido em substancias simples e menos impactantes a longo prazo, enquanto que determinadas condições geológicas, este é escoado para o lençol freático de forma íntegra, acarretando a contaminação e poluição das áreas vizinhas através dos componentes químicos e microrganismos contidos neste.

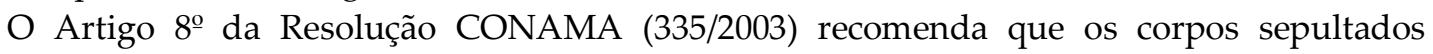
possam ser envolvidos por mantas ou urnas constituídas de materiais biodegradáveis, não sendo indicado o emprego de plásticos, tintas, vernizes, metais pesados ou qualquer material nocivo ao meio ambiente, ficando clara a proibição do uso de material impermeável que impeça a troca gasosa do corpo sepultado com o meio que o envolve, exceto nos casos específicos previstos na legislação.

\subsection{Impactos biológicos}

No âmbito biológico, todos os impactos observados possuem uma magnitude "muito importante", ou seja, de alta relevância, caracterizados por ser temporário, negativo, curto prazo, irreversível, direta e indireta.

Essas magnitudes e alcances foram elencados devido ao fato de que a decomposição envolve a ação de diversas bactérias, cuja atividade trófica culmina na formação de diferentes gases e substancias tóxicas, provocando contaminação química, microbiológica e radioativa do ar, solo e lençol de água em casos de infiltração. A Filtração de microrganismos que entram em contato com o lençol freático é dependente da composição química solo e trocas iônicas com a argila contida neste, influenciando no processo de decomposição da matéria orgânica, filtração e conversão do necrochorume.

Salientamos que a obtenção de resultados mais representativos e precisos nos quesitos "impactos químicos" e "impactos biológicos" demandaria a utilização de técnicas de análise microbiológica e de composição do solo, as quais não foram possíveis de serem realizadas no período de tempo determinado para a realização deste estudo. 


\subsection{Impactos antrópicos}

Considerou-se como pouco importante e positivo a variável "impacto sonoro" e como muito importante e negativo, os itens: "social" e "infraestrutura". Todas as categorias foram qualificadas como de curto prazo e permanentes, sendo explicito que neste ultimo fator considera-se o fato da imobilidade do empreendimento e inviabilidade de desativação devido aos aspectos culturais e religiosos envolvidos no âmbito da representação social e religiosidade a cerca do aspecto mortalidade, influenciando também na qualificação do quesito reversibilidade, no qual o item sonoro foi considerado irreversível, os demais como reversíveis. No O item infraestrutura foi marcado como influência direta e os itens social e sonoro como forma indireta de influência.

No aspecto influencia, foi considerado direta no quesito infraestrutura e indireta nos ambitos social e sonoro, visto que a implementação do cemitério na área em que foi realizada, corrobora para a redução do valor das áreas habitáveis e residências construídas em seu entorno em virtude da percepção da população relativa à cemitérios, corroborando para a baixa mobilidade urbana local e por conseguinte local seguro para praticas marginalizadas.

no âmbito sonoro, em conformidade com moradores residentes no local estudado, só existe maior movimentação de pessoas e veículos, e por tanto, maior produção de poluição sonora em eventos destinados a homenagens aos finados e sepultamentos, razão pela qual este aspecto não foi considerado representativo.

\section{Conclusões}

Considerando os aspectos supracitados a cerca das atividades sepulcrais no cemitério público municipal da cidade de Queimadas, é possível apontar que, mesmo em condições adversas no âmbito físico, como por exemplo, quando se trata do relevo do terreno, a implementação de suas atividades é considerada viável, visto que no contexto histórico da urbanização da cidade em que está localizado, suas atividades precederam a construção de residências e pavimentação de seu entorno, no entanto, neste quesito, considera-se como relevante a adoção de estratégias para a drenagem e pré-tratamento do necrochorume gerado a partir da decomposição dos finados sepultados.

Através de um sistema de drenagem e tratamento do necrochorume, seria possível evitar a contaminação microbiológica, viral e substancial que podem afetar o lençol de freático da região, em especial pelo fato de que este abastece mananciais da cidade e podem provocar, por conseguinte a contaminação da população que estiver em contato, bem como animais que fizerem uso da água.

Recomenda-se também a adoção de um sistema de drenagem da água proveniente do escoamento da chuva para as ruas que lhes dão acesso, bem como atividades de mobilização e conscientização quanto aos riscos de exposição.

\section{Referências}

ALBUQUERQUE, H.N.; CERQUEIRA, J.S.; BARBOSA, J.S. "Os cemitérios de Campina Grande-PB e seus Impactos Ambientais". In: ALBUQUERQUE, H.N (org). Múltiplos saberes da sala de aula às atividades de campo - Campina Grande: Impressos Adilson, 2012.

BRASIL. Conselho Nacional do Meio Ambiente, Resolução no 335, de 03 de abril de 2003. Dispõe sobre o licenciamento ambiental de cemitérios. 2003. Disponível em: $<$ http://www.aguaseaguas.ufff.br $>$. Acesso em: 17/11/2014.

BRASIL. Licenciamento Ambiental de Cemitérios, no Resolução 335, de 3 de Abril de 2003. Disponível em: <http://www.mma.gov.br/port/conama/res/res03/res33503.xml> Acesso em: 20/11/2014. 
LELI, I.T.; ZAPAROLI, F.C.M.; SANTOS, V.C.; OLIVEIRA, M.; REIS, F.A.G.V. Estudos ambientais para cemitérios: indicadores, áreas de influência e impactos ambientais. Bol. geogr., Maringá, v. 30, n. 1, p. 45-54, 2012.

NORMA ISO 14001. Sistemas de Gestão Ambiental, Especificação e Diretrizes para uso. São Paulo, 10 de março de 2003.

MATOS, B.A. Avaliação da ocorrência e do transporte de microrganismo no aquífero freático do cemitério de Vila Nova Cachoeirinha, município de São Paulo. 2001. 113 f. Tese (Doutorado em Recursos Minerais e Hidrogeologia) - Escola Politécnica, Universidade de São Paulo, São Paulo, 2001.

SÁNCHEZ, L.E. Avaliação de Impactos Ambientais: Conceitos e Métodos. São Paulo: Oficina de textos, 2008.

SILVA, L.M. Cemitérios: fonte potencial de contaminação dos aquíferos livres. Anais. Congresso latino americano de hidrologia subterrânea, 4., 1998, Montevideo. Memórias. Montevideo: ALHSUD, 1998. v. 2, p. 667-681.

SILVA, R.W.C.; MALAGUTTI FILHO, W. Cemitérios como áreas potencialmente contaminadas. Revista Brasileira de Ciências Ambientais, n. 9. Abril, 2008. 